\title{
Income-related inequalities in diseases and (1) comanat health conditions over the business cycle
}

\author{
Tinna Laufey Ásgeirsdóttir ${ }^{*}$ and Hildur Margrét Jóhannsdóttir
}

\begin{abstract}
How business cycles affect income-related distribution of diseases and health disorders is largely unknown. We examine how the prevalence of thirty diseases and health conditions is distributed across the income spectrum using survey data collected in Iceland in 2007, 2009 and 2012. Thus, we are able to take advantage of the unusually sharp changes in economic conditions in Iceland during the Great Recession initiated in 2008 and the partial recovery that had already taken place by 2012 to analyze how income-related health inequality changed across time periods that can be described as a boom, crisis and recovery. The concentration curve and the concentration index are calculated for each disease, both overall and by gender. In all cases, we find a considerable incomerelated health inequality favoring higher income individuals, with a slight increase over the study period. Between 2007 and 2009, our results indicate increased inequality for women but decreased inequality for men. Between 2009 and 2012 on the contrary, men's inequality increases but women's decreases. The overarching result is thus that the economic hardship of the crisis temporarily increased female income-related health inequality, but decreased that of men.
\end{abstract}

Keywords: Equality, Distribution, Health, Diseases, Income, Business cycles

JEL classification codes: $11,114,115$, E3

\section{Background}

As the income gap between the richest and the poorest widens, the importance of monitoring health disparities across the income spectrum rises, and the debated amount of appropriate government spending on health care makes income-related health inequality an even more relevant subject to study. The importance of tracking how health is distributed along the income spectrum is made even clearer by the fact that the potential gains from publicly provided health care is not only improved public health but also minimized socioeconomic health disparities.

Although studies on the income-related distribution of health in general have been extensive and the knowledge of the effects of business cycles on health has improved, the understanding of how business cycles affect incomerelated distribution of diseases and health disorders is much more limited. Using data from a survey on health

\footnotetext{
* Correspondence: ta@hi.is

Department of Economics, University of Iceland, Oddi v/Sturlugotu, Reykjavík, Iceland
}

and well-being conducted by the Directorate of Health in Iceland, this paper seeks to explain how the prevalence of thirty diseases is distributed across the income spectrum. Specifically, we examine this during a very turbulent economic period in Iceland, including a boom (2007), a subsequent bust (2009), and a period of partial recovery (2012). We thus take advantage of the unusually sharp change in economic conditions in Iceland during the Great Recession in 2008 and analyze how income-related health inequality changed across the different time periods.

As our study combines income inequality, health and business cycles, it can be seen as a contribution to at least two strands of literature; on the one hand, the relationship between income (income inequality) and health, and on the other hand, the relationship between business cycles and health. Therefore, the literature review is split in three parts; firstly, it discusses previous studies on the association between income inequality and health, secondly, it provides an insight into business cycles' effects on health and lastly, income-related health 
inequality and business cycles will be discussed followed by a brief discussion on the Icelandic context.

\section{Health, income and inequality}

A range of studies indicate a positive correlation between income and health, although the causality remains hard to determine [1-4]. Many economists refer to social factors such as education and labor-market participation as the most important determinants of this correlation and point out that educated individuals are better suited to understand health information and hence in a better position to reap the benefits of healthcare systems and choose a healthy life style than their less educated counterparts $[5,6]$. Those same individuals also tend to have higher income, and many argue that higher income discourages risky health behavior and reduces the risk of health disorders, although health behavior has also been associated with income independent of education [7-9]. The reason here can for example be that incentives may be relatively greater to prolong life that is lived in relatively better economic circumstances.

The abovementioned hypothesized pathways focus on individual-level determinants of income-related health disparities. However, those may be suppressed or elevated by society-wide determinants, such as social, cultural and institutional settings. Although not conclusive at this point, a body of literature has indicated that in general, worse health can be found in societies with more unequal income distributions and numerous studies have concluded that more equal societies not only have better health $[3,4,10]$ but also less health inequalities [11, 12]. Wilkinson and Pickett [4] argue that the association between income inequality and health is strongest when income inequality is measured across whole societies and that better health in more equal societies can be explained through stronger social relationships, social cohesion, trust, lower violence rates and less social distance.

Ásgeirsdóttir and Ragnarsdóttir [13] examine concentration indices for 26 European countries and find relatively extensive income-related health inequality in the Nordic countries, a result that has also been found by other researchers [14-18]. Ásgeirsdóttir and Ragnarsdóttir [13], shed light on the relationship between societal conditions and income-related health inequality, for example GDP. However, they do this cross-sectionally across countries. Although this is relevant, especially as Iceland is one of those Nordic countries examined, the focus of the current project is on rapidly changing ambient economic conditions within a country. In that regard it should be noted that Ásgeirsdóttir and Ragnarsdóttir [13] did not find a systematic pattern between countries' GDP and incomerelated health inequality. However, although GDP across countries may not be associated with the inequalities examined, this does not have to be the case for GDP levels over time within the same country - namely the business cycle. It may very well be that a variable that is generally positively associated with GDP across countries is counter-cyclical within a country. In fact health is a case in point, as population health generally increases with increased prosperity, while still being countercyclical by many estimates as discussed in the following section.

\section{Health and business cycles}

A wide range of studies has shown that recessions generally have a positive impact on public health [1, 9, 19-27]. Ruhm and Cawley [9] add that in accordance with these findings, mortality rates have proven procyclical, driven by mortality that can be explained by life-style decisions, such as coronary heart disease and traffic accidents. Ruhm and Gerdtham [27] studied macroeconomic fluctuations and health in the OECD countries and reported that decreases in unemployment rate during the period 1960-1997 are associated with substantial increases in death caused by diseases such as cardiovascular disease, liver disease, influenza as well as deadly accidents and Ruhm [26] shows that over the period 1972-1991, temporary economic downturns in the United States reduced eight of ten sources of fatalities.

Ruhm and Cawley [9] suggest two mechanisms likely to explain these counter-cyclical health effects; firstly, they mention that less disposable income during recessions reduces unhealthy consumption (see also [28, 29]), secondly, they argue that during recessions, people tend to have more time for healthy behavior (e.g. exercise), since working hours are usually pro-cyclical (see also [30-32]). Others have pointed out that health can be seen as a production input, and hence when working hours are extended, people's health is affected, especially in cyclically sensitive sectors (such as construction), which indeed tend to be characterized by unhealthy or even dangerous working conditions [27, 33-35]. Ruhm [36] emphasizes that although the general results show that health improves in hard times, there are studies that indicate that mortality has become less pro-cyclical over the last few years (e. g. [37]) and even countercyclical [38, 39]. The important fact should also be mentioned that the results appear to be somewhat disease specific; Ruhm [26] shows that although physical health appears to be countercyclical, mental health has often been measured as pro-cyclical and Ruhm [36] finds that mortality due to cancer has over the last years become counter-cyclical, and suicide rates declined in economic upturns. 
Income-related health inequality and business cycles: The Icelandic context

Although the effect of business cycles on income-related health inequalities has received much less attention, Ásgeirsdóttir's and Ragnarsdóttir's recent study [40] does focus on income-related inequality in health in Iceland using data from 2007 to 2009 , a year pre and post the Icelandic economic collapse. Their results indicate prorich income-related health inequality and they find that the effects of the crisis substantially differ between males and females. For men, income-related health inequality increased after the crisis while for women it remained rather stable. They use data from surveys conducted in 2007 and 2009, but as a first attempt at this examination, they only use a very general one-variable health measure, namely self-assessed health. They call for further research examining this relationship using more specific measures of health. Such an analysis is presented in the current study.

Iceland's economy was hit hard by the Great Recession with considerable societal effects. Icelanders experienced, in a relatively short period of 5 years, an economic boom, followed by a sudden bust and then substantial recovery. These rapidly changing economic conditions make the years of 2007-2012 an ideal time period to examine the recession's effects on incomerelated health inequality in Iceland. Although only Ásgeirsdóttir and Ragnarsdóttir [40] have examined the business-cycle effects of the collapse on income-related health distributions, the special research opportunity created by those dramatic circumstances in Iceland has been taken advantage of in multiple studies examining the effect of the crisis on health $[13,41-44]$ and health behaviors [45-50]. Due to the incredibly low pre-crisis unemployment rate (of only $2 \%$ in October 2007) the large percentage increase in unemployment during the crisis still resulted in a lower rate (of $6 \%$ in October 2009) than in most other hard-hit countries such as Spain and Ireland $[46,51]$. However, while these countries experienced a deflation during the crisis, in Iceland, on the contrary, prices rose due to a devaluation of the Icelandic Krona by about 36\% in exchange markets [46]. This was evident both from the consumer price index which increased by roughly $12 \%$ between 2007 and 2008 and again 12\% between 2008 and 2009 and from more than 10\% drop in real wages between 2007 and 2010 [52]. While this obviously reduced people's purchasing power, it also had detrimental effects on Icelanders' debt obligations, especially those in foreign currencies [47]. Already by 2010, the CPI increase reverted back to its pre-crisis level (with annual increases of 3-5\% between 2010 and 2012) and real wages to their preboom level [46, 47, 52]. This rapid recovery, which indeed was lauded in international news stories, has mainly been explained by three important factors: capital controls, a flexible labor market and flexible exchange rates $[46,53,54]$.

Using data from the same survey as Ásgeirsdóttir and Ragnarsdóttir [40], as well as an additional wave of data from 2012, this paper seeks to extend the contribution of their study in two ways. Firstly, by extending the study period to include economic recovery. Secondly, by extending the depth of the analysis from one selfassessed health variable, to examining thirty different diseases and health disorders. These are eye disease (e.g. cataracts or glaucoma), irritable bowel syndrome, chronic fatigue syndrome, cold/flu, alcoholism (or substance addiction), chronic anxiety, chronic depression, anxiety, serious worries, sleeping difficulties, other mental disorders, shortness of breath, debility, myalgia, back/ shoulder pain, arm pain, leg pain, frequent headaches, toothache, abdominal pain, rheumatoid arthritis, osteoarthritis, fibromyalgia, chronic back syndrome, chronic throat disease, diabetes, serious headaches, urinary incontinence, thyroid disease and high blood pressure. We examine the distribution of those diseases and conditions over the time period of interest by calculating concentration indices for each disease with respect to households' disposable income, both gender specific and overall and comparing the indices across years.

The additional data from 2012 strengthens the study in various ways. It allows us to determine whether or not the effects of the collapse in 2008 reversed with the recovering economy. This is important, as it sheds light on whether observed changes are likely to be due to the economic conditions or underlying time trends in health distributions. Also, a limitation of the first two waves is that no additional individuals were sampled, leading to an overall aging of the sample between waves. With the additional wave from 2012, new participants with the same age range as the first sample in 2007 were added, allowing us to examine to what extent the changes are driven by the aging of the sample. As indicated above, the contribution of this study is partly the detailed analysis across different health conditions and diseases, whereas Ásgeirsdóttir's and Ragnarsdóttir's [40] study only used one general measure of self-assessed health. It should also be mentioned that although the relation between some of those diseases and income has already been examined, the changes in the income-related distribution of those diseases has not been examined specifically across the business cycle.

\section{Data}

The data stems from the survey "Health and well-being", conducted by The Directorate of Health in Iceland in October 2007, 2009 and 2012. The survey includes variables on health, demographics and income. In October 
2007, a stratified random sample of 9.711 Icelanders received the questionnaire with a net response rate of $60,8 \%$. In 2009, every participant who had agreed to be contacted again received a questionnaire again. That year, the response rate was $69,3 \%$, corresponding to $42,1 \%$ of the original sample participating in the first two waves of the survey. In 2012, a third wave of the survey was sent to 10,093 subjects, 3,659 respondents from the original sample and a new sample of 6,434 participants. The response rate of the new sample was $55,0 \%$, resulting in 3,537 new answers and the response rate of the original sample was $88,7 \%$, resulting in 3,246 individuals answering all three waves. Having eliminated observations with missing values on key variables, the final sample consisted of 9,963 observations on 6,446 individuals. For each regression, the final sample then depended on the number of missing values for the particular variables applied in the calculations.

We use thirty binary variables for health dummies, each representing a specific health disorder or disease mentioned above, taking the value 1 if an individual is suffering from the disease and 0 otherwise. The income variable is derived from the question: In what range do you estimate your household's income over the last 12 months? Fourteen response options ranged from "below 900 thousand" (7.064 USD) and "above 18 million" (141.287 USD) and the responses were coded as the midpoint of each interval. As the last option "above 18 million" had no upper bound, responses in that range were coded as 20,5 million.

In order to make households' income comparable between different household compositions, the OECD modified equivalence scale was applied. The equivalence scale addresses the concept of economies of scale within the household and hence the notion that a household's needs increase with every additional member, but not proportionally. To take this into account, each member was assigned a value $(0-1)$ indicating his/her needs for resources relative to the others'; in particular, the first adult was assigned the value 1 , every additional adult (over the age of 18) was assigned the value 0,5 and children were assigned 0,3 . Although the OECD modified equivalence scale sets the child-adult cut-off at the age of fourteen, we categorized all individuals under the age of eighteen as children, due to data limitations. Subsequently, to obtain the equivalent household income variable used throughout the research, each household's income was divided by the sum of all its members' values making the income variable comparable between different household compositions as a measure of the financial means of the individual at hand [55].

\section{Methods}

The methodology was based on the concentration curve and the concentration index. The concentration curve is built on the idea of the Lorenz curve but instead of plotting the cumulative portion of the population against $\mathrm{cu}$ mulative portion of total income, it plots the cumulative portion of a health variable against the cumulative portion of the sample, ranked by income [56-59]. In our case, in order to address the relationship between the distribution of particular diseases and the distribution of income, the $\mathrm{x}$-axis represents the cumulated population, ranked by household income (poorest-richest) and the yaxis represents cumulated health (the absence of one of the thirty diseases of interest each time). Thus, a straight diagonal $45^{\circ}$ line would represent perfect income-related health equality (line of perfect equality) where every income group has the same prevalence of a certain disease. A curve below the line of perfect equality indicates better health concentrated among those with higher income and a curve above the line of perfect equality indicates better health concentrated among those with lower income.

The concentration index, derived from the concentration curve, resembles the Gini coefficient and quantifies the health-income inequality graphed by the concentration curve. The concentration index is defined as twice the area between the concentration curve and the line of perfect equality. It ranges between -1 and 1 where 0 indicates perfect equality and -1 and 1 stand for perfect inequality, favoring low income groups $(-1)$ and high income groups (1). Formally, the concentration index is calculated by the following formula:

$$
C I=1-2 \int_{0}^{1} L(s) d s
$$

where $L(s)$ is the cumulative distribution of health, as a function of cumulative income, s. This can be computed by using the following formula, with individual level data:

$$
C I=\frac{2}{n \mu} \sum_{i=1}^{n} y_{i} R_{i}-1
$$

with $y_{i}(i=1, \ldots ., n)$ as the health score of individual $i, \mu$ as the mean level of health and $R_{i}$ as the relative rank by individual $i$ 's income [12, 18, 40, 57, 58].

Since our health variables are binary, calculations will be built on the Wagstaff Concentration Index (WCI), which is a slightly varied version of the concentration index. As Wagstaff [60] suggests for binary health variables, we normalize the $\mathrm{CI}$ by dividing it through by the reciprocal of the mean of the variable in question $(1-\mu)$ : 


$$
W C I=\frac{2}{n \mu(1-\mu)} \sum_{i=1}^{n} y_{i} R_{i}-1
$$

The WCIs are calculated for each health variable each year, 2007, 2009 and 2012, followed by an inter-temporal comparison of the indices. As both health and labormarket outcomes can vary by gender, all estimations are run separately for males and females, as well as for the full sample. Having computed the WCIs of the 3 years we also compute the WCIs of the new-entry sample of 2012 (Sample 2), which had the same age range as the first sample (Sample 1) had in 2007. A comparison of the two samples gives us an idea of whether the changes in the WCIs of Sample 1 are partly driven by the aging over the 5 year period.

The WCI measurement does not take into account how unavoidable factors, such as age and sex, play a role in the inequality. This can be addressed using decomposition analysis, allowing us to partition the indices into unavoidable and avoidable inequality. Specifically, by decomposing the WCI into its various determinants, we isolate the unavoidable factors and calculate standardized WCIs by subtracting the unavoidable inequality due to gender and age. For each WCI, the decomposition is conducted using the following linear regressor model:

$$
y_{i}=\propto+\sum_{k} \beta_{k} x_{k_{i}}+\varepsilon_{i}
$$

where $y_{i}$ stands for the health measure for individual $i$, $x_{k_{i}}$ is a determinant of health for regressor $k$, and $\varepsilon_{i}$ is the error term. The determinants used in the regression are equivalized household income, marital status, population density and number of people in household. Given $y_{i}$ and $x_{k_{i}}$ we can rearrange and write the WCI as:

$$
W C I=\sum_{k}\left(\frac{\beta_{k} \bar{x}_{k}}{\mu}\right) W C I_{k}+\frac{G W C I_{\varepsilon}}{\mu}
$$

where $\mu$ is the mean of the health measure $y, \bar{x}$ is the mean of the health determinant $x_{k}, W C I_{k}$ is the WCI for $x_{k}$ (the contribution from each determinant $k$ to incomerelated health inequality) and the residual is $G W C I_{\varepsilon}$, the generalized WCI for the error term. The residual thus contains income-related health inequality not explained by variations in determinant $x_{k}$ across the income spectrum $[12,18,40,57]$.

The data were analyzed in Stata 13.0 software [61].

\section{Results}

Tables 1, 2 and 3 show summary statistics for males, females, and full samples respectively. Calculations are based on those who answered all the waves (Sample 1), and the last column, 2012a, shows new-entrants in 2012 (Sample 2).
For the overall Sample 1, the frequency of the diseases and conditions increase over the period. For all 3 years, (and both samples) the summary statistics indicate higher prevalence of the diseases for women than for men.

This increase in disease prevalence is especially noteworthy between 2009 and 2012, thus on average, health is pro-cyclical between 2007 and 2009 but counter-cyclical between 2009 and 2012. This highlights the importance of having three waves to distinguish the effects of the changing economic environment from time trends, as well as the new sample of 2012 to shed light on the effects of the aging of the panel. Men's health is not affected by the economic collapse in a substantial way, the average frequency in the diseases rises by only $4,9 \%$ between 2007 and 2009 and increases by 7, 3\% between 2009 and 2012. Women's health is more volatile, with the average frequency increasing by $4,2 \%$ between 2007 and 2009 and 11,5\% between 2009 and 2012. Quite surprisingly, Sample 2 does not seem to be healthier than Sample 1 in 2012, despite the age difference. Although the trend in the average frequency of diseases is pro-cyclical between the first two waves and counter-cyclical between the latter two, the trends differ between diseases; for example, alcoholism is pro-cyclical over the whole period and mental illness (chronic anxiety, chronic depression and other disorders) has a counter-cyclical trend over the whole period.

Although the summary statistics are useful in order to study the impact of the recession on the prevalence of the diseases, our main results are listed in Tables 4, 5 and 6 . These show the unstandardized and standardized Wagstaff Concentration Indices for each of the diseases/disorders. Table 4 represents the WCIs for men, Table 5 for women and Table 6 for the total sample. Again, the first three columns of the tables represent the WCI of Sample 1 (those who replied to the survey all three times) and the fourth column shows the WCI of Sample 2 (those who only replied in 2012).

On average, for both genders, better health is concentrated among those with higher income over the whole period. Our results show an increase in income-related health inequality among women over the years 20072009, but a decrease (to a lesser extent than the increase) between 2009 and 2012. For men, on the contrary, inequality increased over the first period but decreased over the second, less than it rose over the first. On the whole, income-related inequality increased for both men and women from 2007 to 2012, as the increase exceeded the decrease for both gender, and therefore the overall indices suggest a steady increase over 


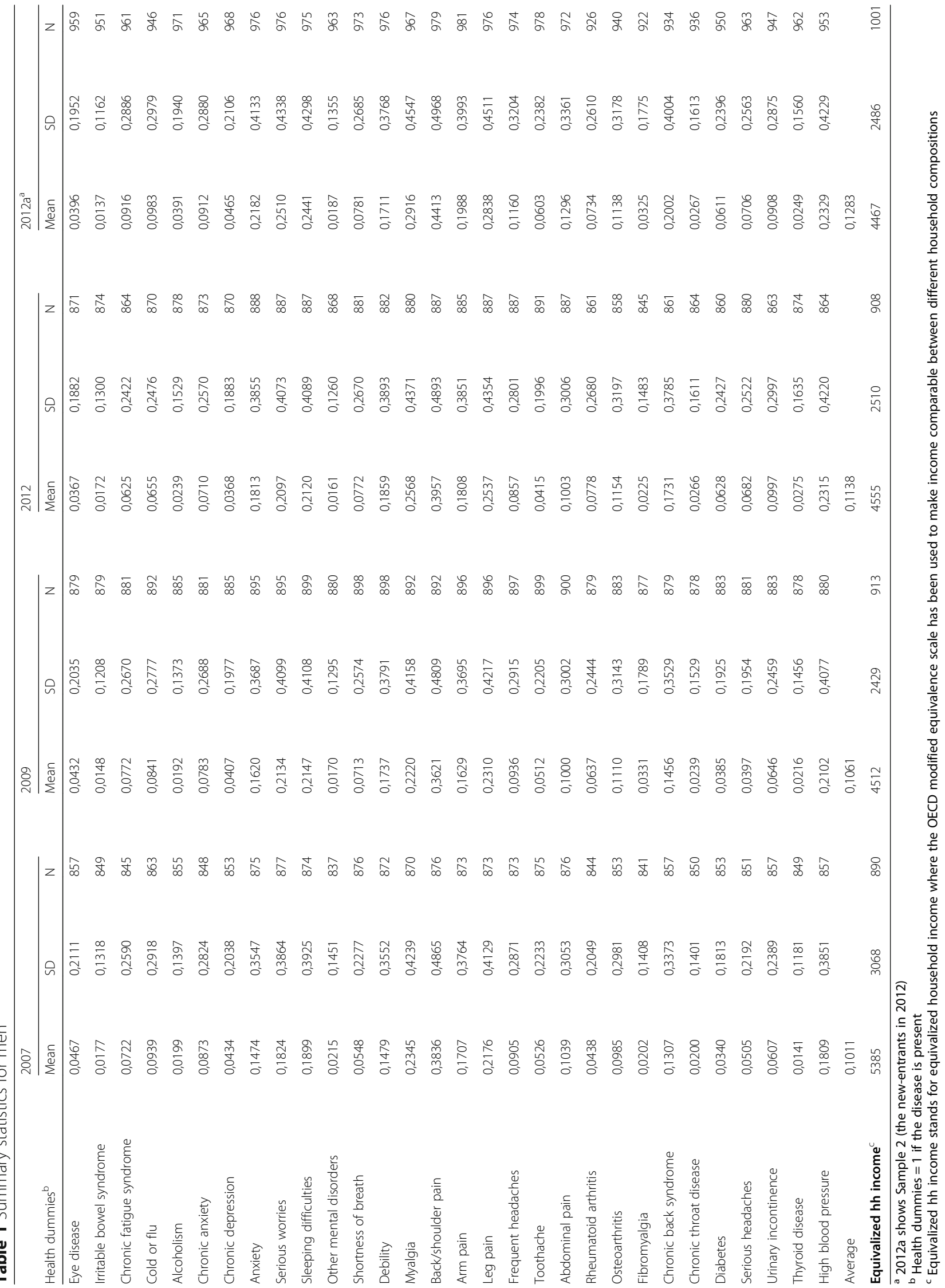




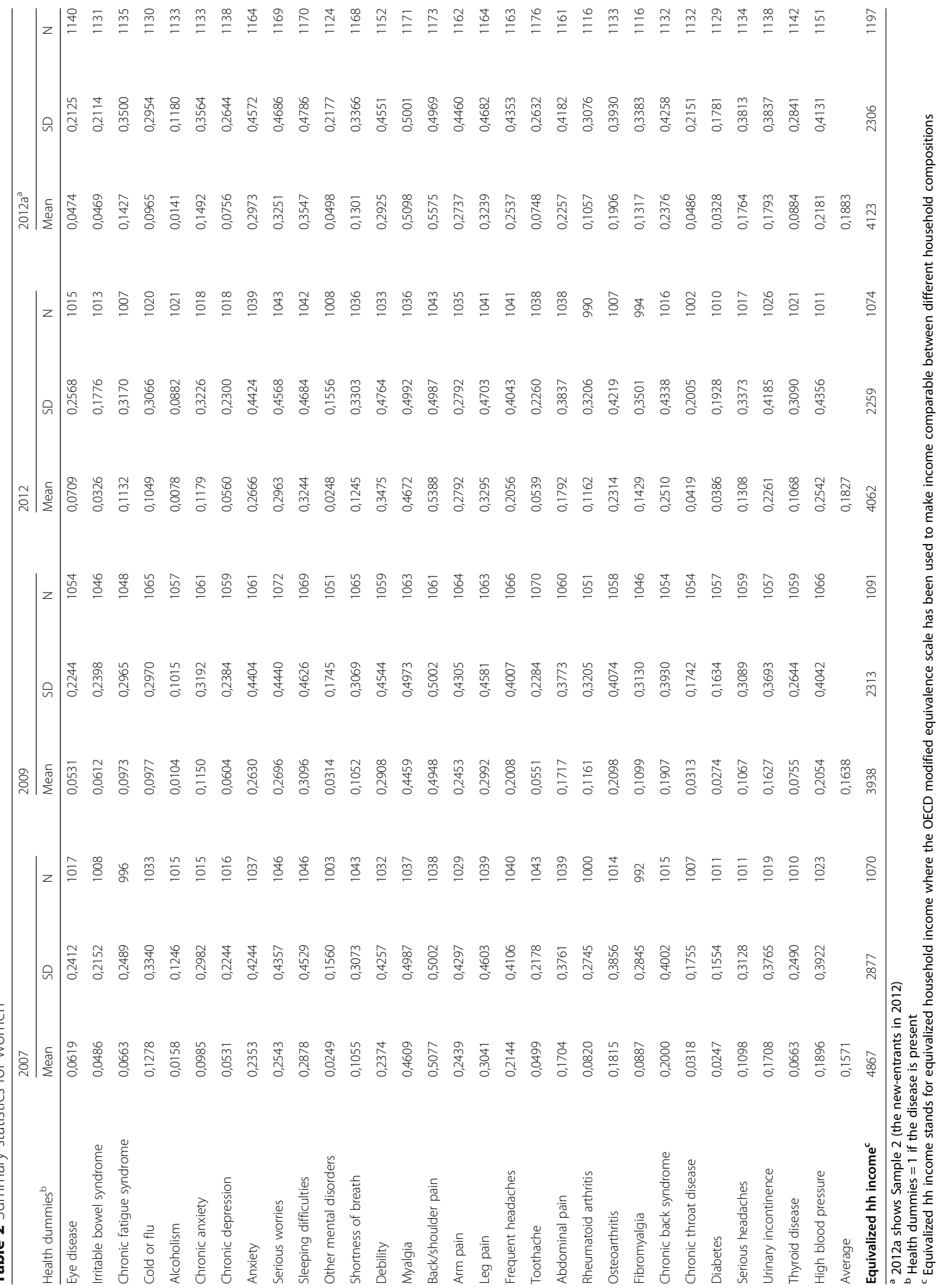




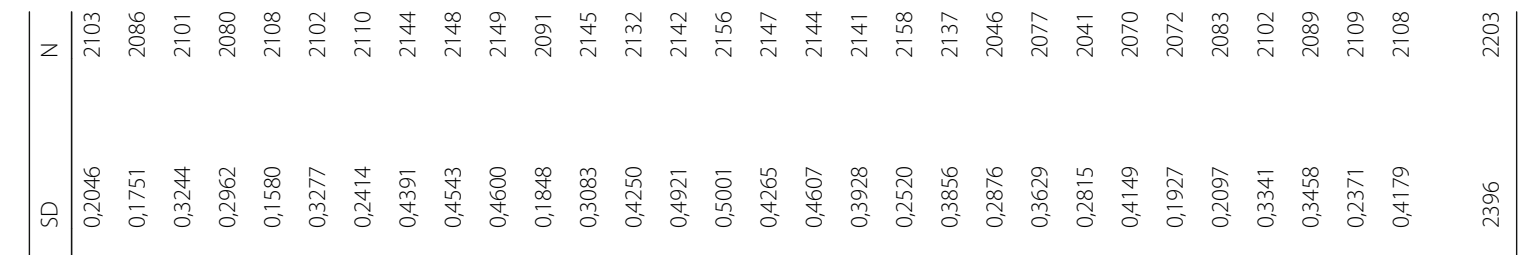

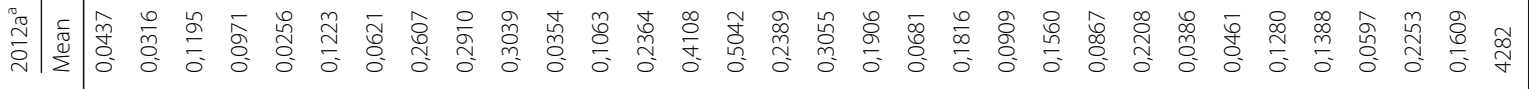

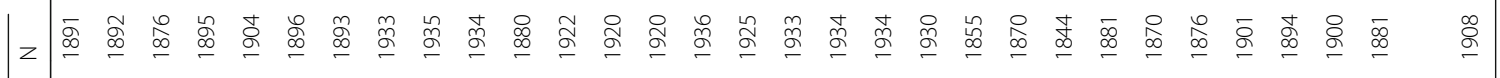

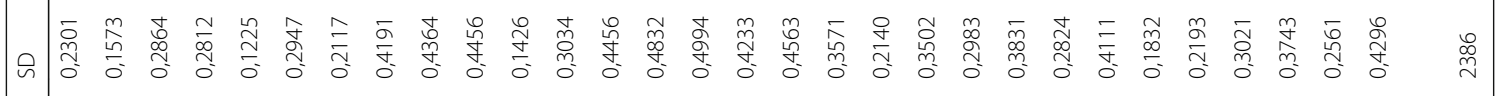

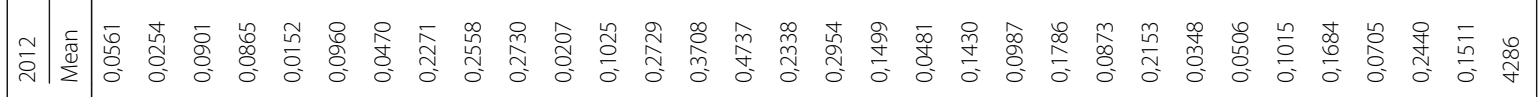

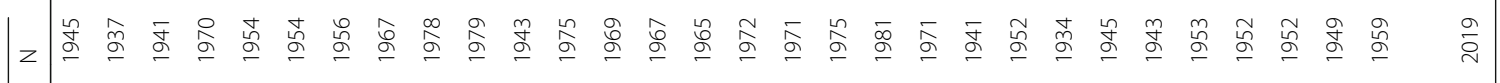

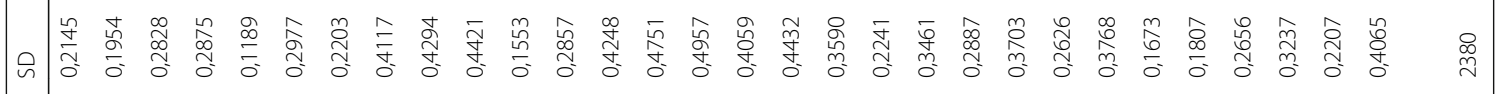

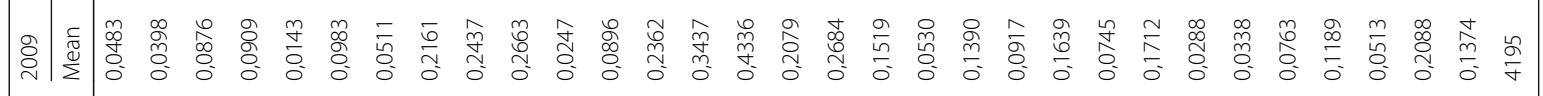

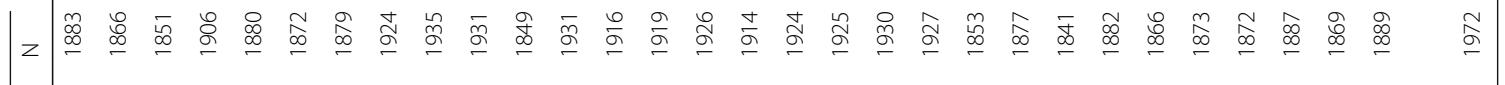

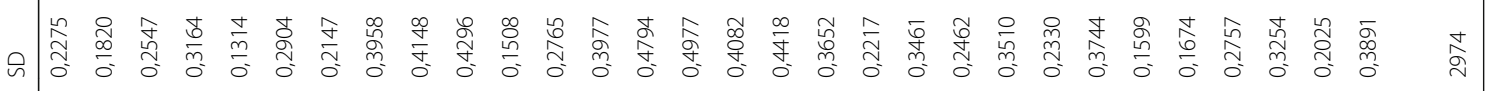




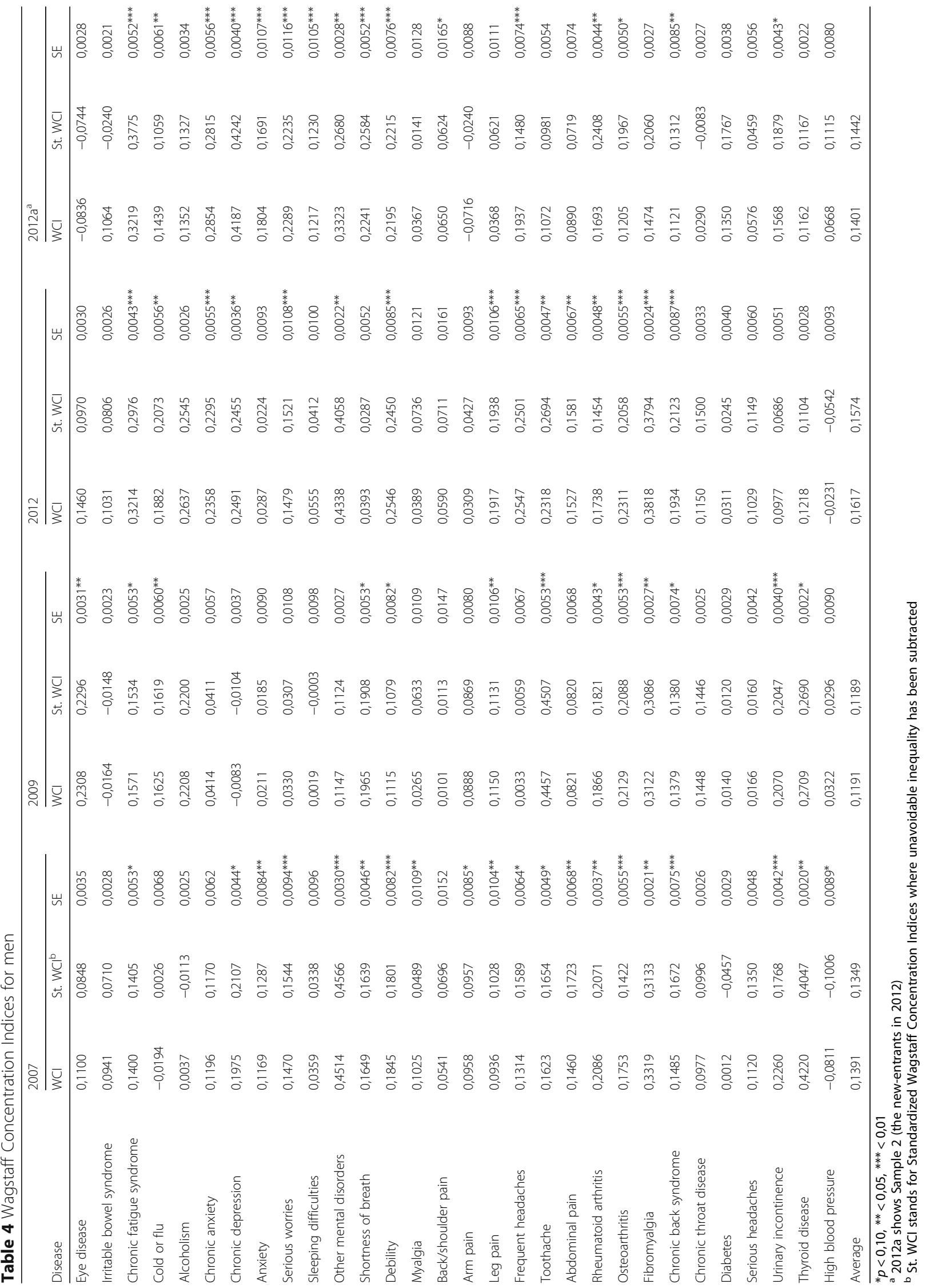




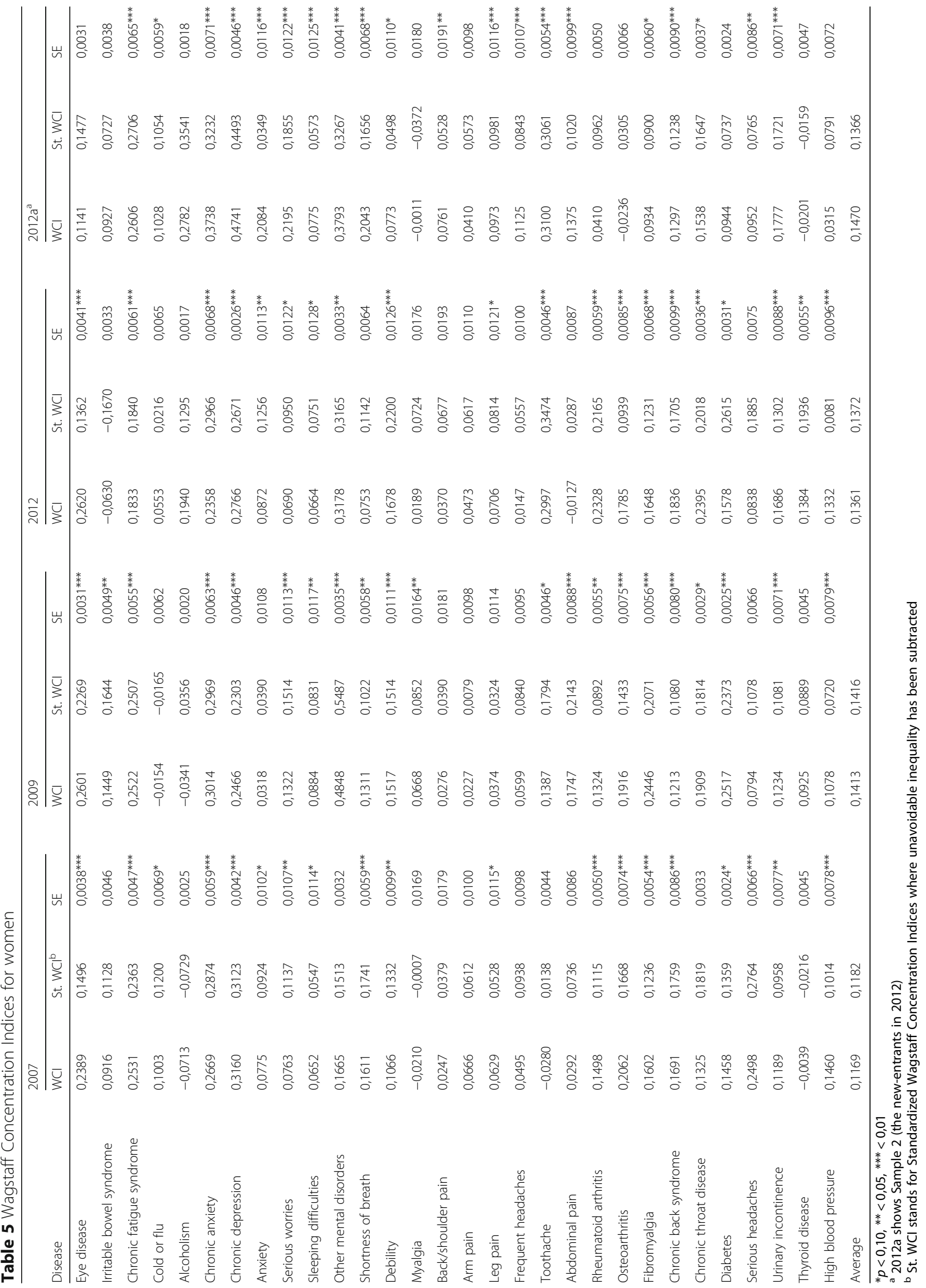




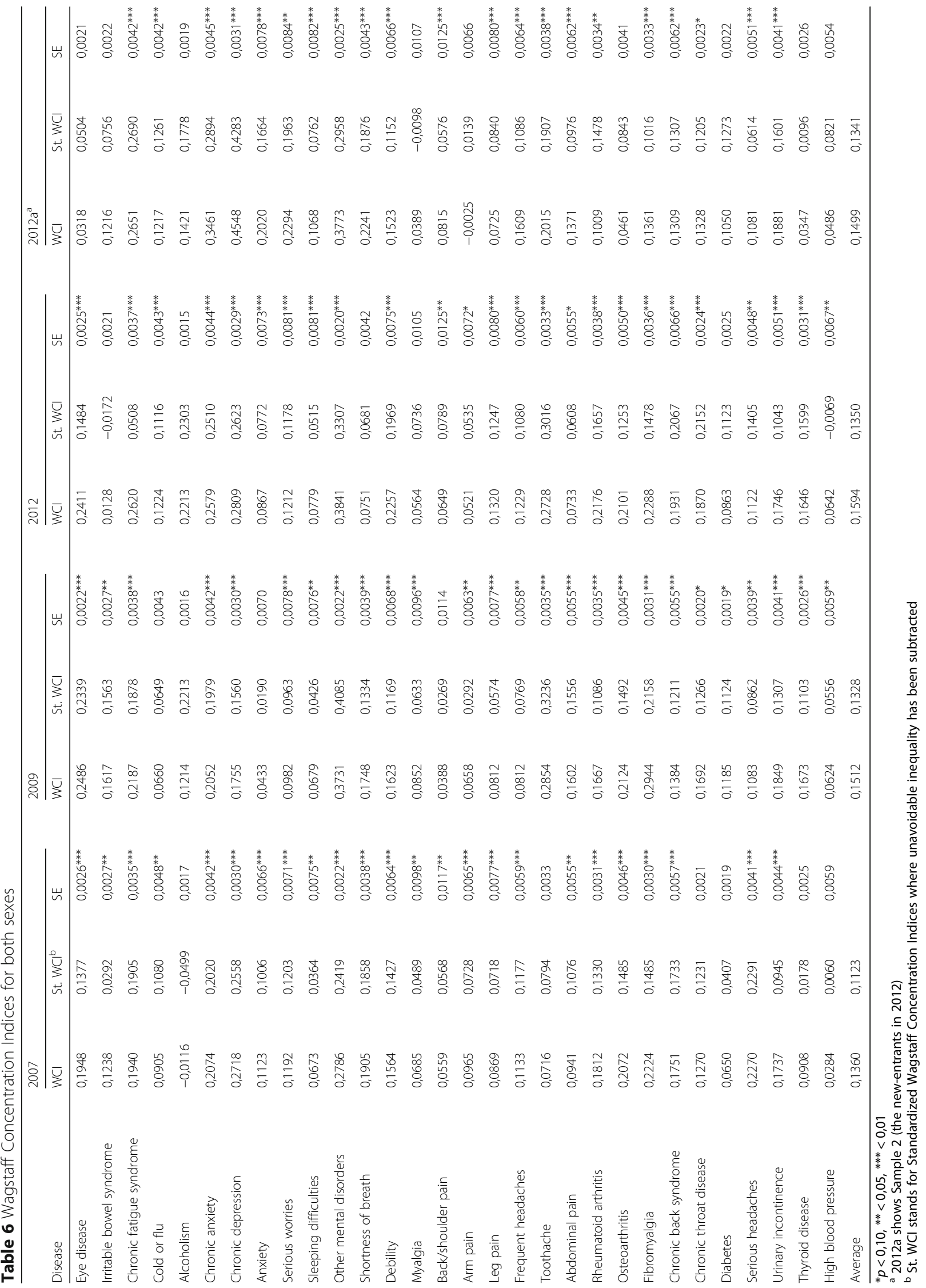


the whole period, first driven by the increase in women's inequality and then by men's. Figure 1 graphs the main results by showing the average WCIs, both by gender and overall.

The panels in Fig. 2 graph the trends of the disease specific WCIs, separately for males and females, as well as overall. With only few insignificant exceptions, they all show income-related inequality favoring higher income groups (with WCIs ranging from around zero to 0,5 ).

Relatively high income-related inequality can be seen for the mental conditions - chronic anxiety (panel f), chronic depression (panel g), and other mental disorders (panel k) - and in all cases the inequality is higher for women than for men. For alcoholism or substance addiction (panel e) the WCIs for both genders have increased steadily over the entire period and are substantially higher for males than females. Toothache (panel s) and fibromyalgia (panel $\mathrm{w}$ ) have also relatively high WCIs for both genders, and again higher for men than women. The income-related inequality in toothache has a clear trend with a rapid increase around the recession, but a slight recovery between 2009 and 2012 .

The most stable WCIs are those connected to physical pain - such as myalgia (panel $\mathrm{n}$ ), back/shoulder pain (panel o), arm pain (panel p), leg pain (panel q), and both headache variables (panels $\mathrm{r}$ and a1) - and these WCIs tend to have a slight decrease between 2007 and 2009 and a small increase between 2009 and 2012. A relatively steady WCIs can be found for arthritis, both rheumatoid arthritis (panel u) and osteoarthritis (panel v).

\section{Discussions}

Our findings contribute to existing studies on incomerelated inequality in health, and our research is - to our best knowledge - the first to look at the impact of an economic collapse on the income-related inequality in

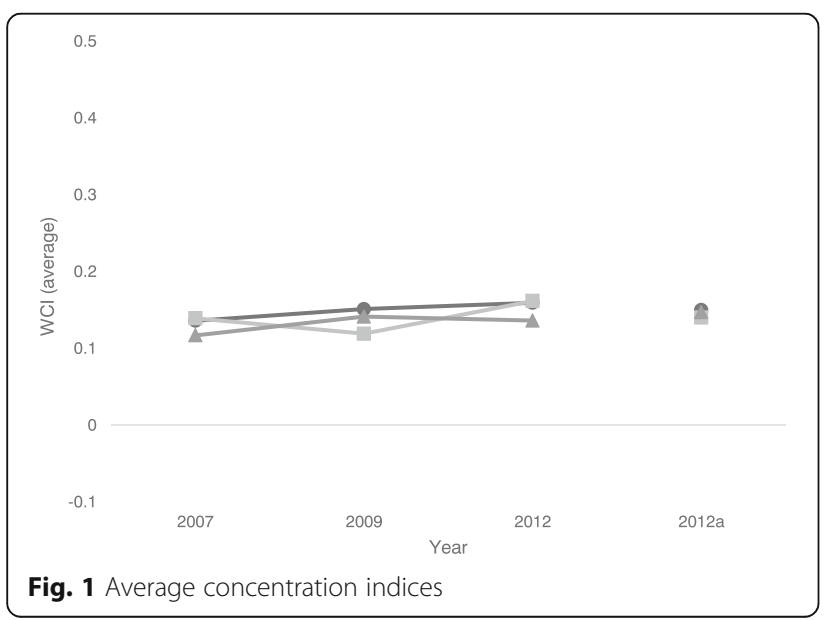

specific diseases and disorders. As mentioned earlier, the current study can be seen as an extension of Ásgeirsdóttir's and Ragnarsdóttir's paper [40] on the impact of the economic collapse on income-related health inequality in Iceland over the period of 2007-2009. With additional data from 2012 we were able to study the impact over a longer period, and while they used a general health measure we measure health specifically for thirty different diseases.

A large proportion of government spending in Western countries goes to health care, which makes it important to monitor socio-economic inequality, in particular incomerelated health inequality. As our study provides a valuable insight into the distribution of various diseases along the income spectrum in Iceland we hope our results can be of practical value.

The unusually sharp changes in the economic conditions in Iceland over the short time period examined allowed us to study the business cycle's effects without being considerably affected by long-term changes in other variables which have caused methodological challenges in studies conducted over a longer time period. Furthermore, the timing of the collection of the data, which includes both income and health variables, enables us to take full advantage of these rapid changes as the first wave is collected a year before the economic collapse, the second wave a year after the collapse and the third 4 years after the crash, when the economy had already partly recovered.

Our results suggest a considerable income-related health inequality in Iceland over the years of 2007-2012. On average the higher-income individuals are healthier than their lower-income counterparts. On the whole, income-related health inequality increased steadily over the whole period, although the economic hardship of the crisis caused a temporary decrease in the case of males but an increase for women. For both genders, these temporal trends in the WCIs over the first period are reverted in the latter period during the recovery. It should also be mentioned that these opposing trends in the gender specific WCIs are most distinct in the trends of the mental health variables.

The gender differences in the WCIs highlight the importance of taking into account unavoidable factors by calculating standardized WCIs. For the full samples (both sexes), the standardized indices are substantially lower than the unstandardized ones. However, the differences between the standardized indices and the unstandardized are very small for the gender specific WCIs (where age is the only unavoidable factor). Clearly, the overall differences between the standardized WCIs and the unstandardized WCIs are driven by the large contribution of gender differences. In many cases, clear gender differences can also be observed in the impact of the recession on health, and our summary statistics reveal 


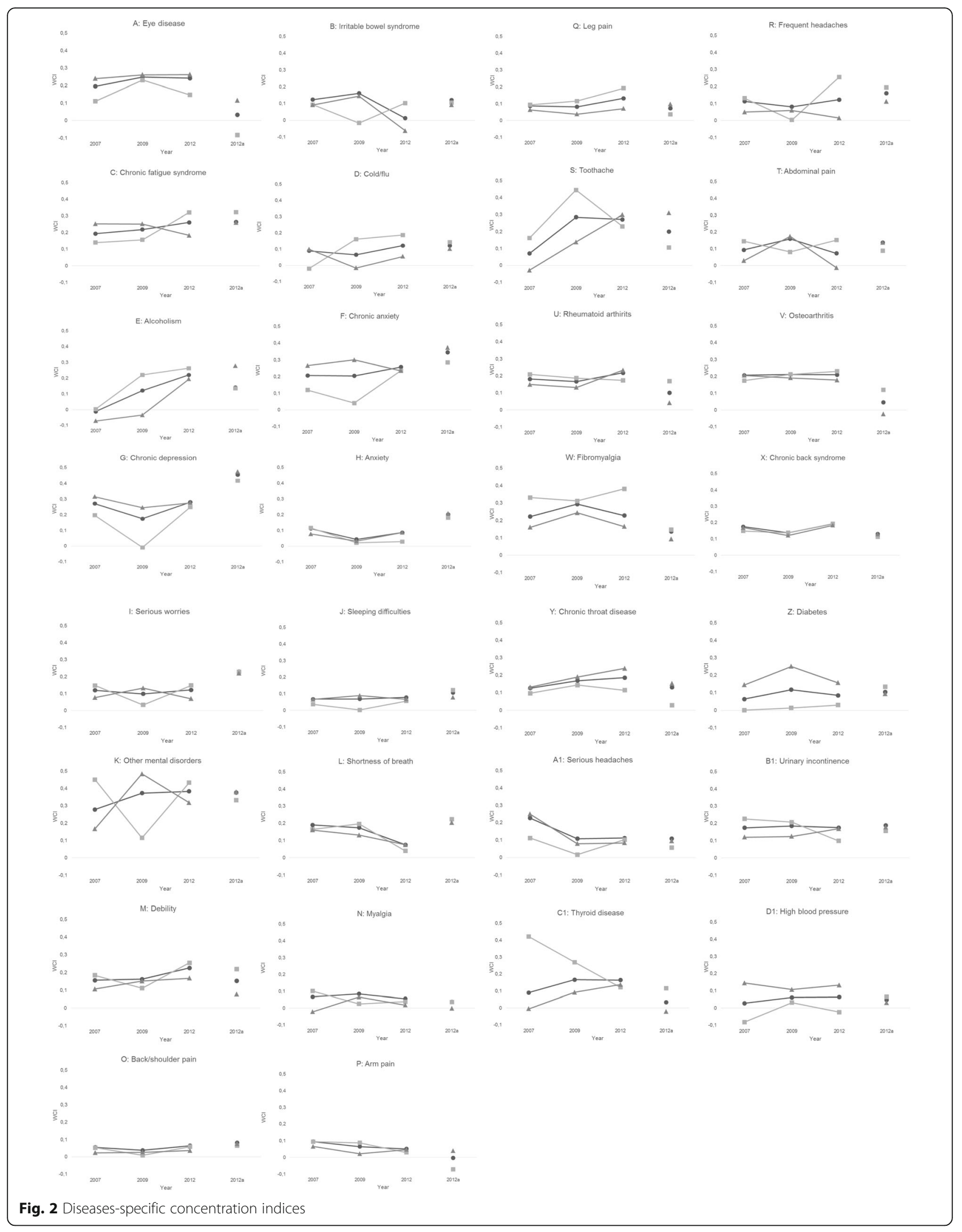


worse health and lower income for women than men over the whole period (results also found by Ásgeirsdóttir and Ragnarsdóttir [40]).

Furthermore, there are obvious gender differences in the trends of the WCIs; as mentioned above. During the economic downturn in the 2007-2009 period, women's income-related health inequality increased while that of men's decreased. During the recovery, in the 2009-2012 period, female inequality decreased and men's increased. Although we can only hypothesize about the reasons behind the gender differences in the WCI trends, the decrease in men's WCIs between 2007 and 2009 might be due to increased unemployment in cyclically sensitive sectors, such as construction industry, in which many studies have found counter-cyclical health trends as mentioned above. Increased unemployment in these sectors, which tend to be dominated by men, would then cause individuals to drop in the income ranking while improving in health, which lowers the WCIs. Our summary statistics support this hypothesis; physical health (especially physical health variables that are likely to be related to hard work such as myalgia, back/shoulder pain, arm pain, abdominal pain and serious headaches) improves during the recession (between 2007 and 2009). Regarding the increase in female income-related health inequality over the crisis period one might speculate whether these trends can be explained by different effects on different income groups: we suggest that women in higher income groups are more likely to follow Ruhm's and Cawley's [9] counter-cyclical health mechanisms mentioned above; during a recession they reduce their unhealthy consumption and increase healthy behaviors, such as exercise. Their lower income counterparts, on the other hand, might be more likely to be adversely affected by the recession, in particular less disposable income might affect their mental health. This hypothesis is also somewhat supported in our summary statistics; many of our physical health variables suggest that women's physical health improves during the crisis but their mental health clearly deteriorates. The lower average income of females, relative to men, could potentially explain why a decrease in income during the crisis had larger effects on women's mental health than men's. However, the reason for this gender difference remains unclear and would be an interesting avenue for future research. Importantly, the fact that the average incomerelated health inequality for both genders reverts back towards their pre-crisis levels as the economy recovers from the recession (over the 2009-2012 period) makes the observed changes even more likely to be due to the economic conditions.

Quite surprisingly, the changes in our gender specific WCIs over the first period (2007-2009) are not in accordance with those of Ásgeirsdóttir and Ragnarsdóttir
[40] who concluded a decreased inequality for women, but an increased inequality for men. Here it should be noted that it is in our WCIs for mental health (such as chronic anxiety (panel $\mathrm{f}$ in Fig. 2), serious worries (panel $\mathrm{i}$ in Fig. 2), other mental disorders (panel k in Fig. 2) and sleeping difficulties (panel $j$ in Fig. 2)) that drive the rise in women's WCIs and the decrease in men's is most distinct. In this respect it is important to bear in mind that Ásgeirsdóttir and Ragnarsdóttir [40] use a very general self-assessed health measurement and people's assessment is more likely to reflect physical health than mental health. This might partly explain the inconsistency between the results and highlights the importance of a more detailed analysis as the one presented here.

Our summary statistics show some consistency with the results of several studies mentioned earlier on the impact of business cycles on health; counter-cyclical physical health but pro-cyclical mental health $[26,27,36]$. In our results, such effects can be observed to some extent over the period 2009-2012. As Iceland's economy recovered rapidly from the recession, physical health deteriorated, but some of our mental health variables indicate an improvement. However, over the first period, the average frequency of diseases remains very stable. The negative impact of the crisis on mental health is consistent with studies on other hard hit European countries such as Greece [62] and Spain [63]. However, a recent study [64] shows that in these countries, the crisis had larger adverse effects on health in general than in Iceland and suggests that this is due to the stark differences in fiscal policies adopted during the recession.

When crudely observing cyclicality from the summary statistics, the aging of the sample needs to be kept in mind. Despite the lower age range, Sample 2 has slightly higher frequency in diseases on average than Sample 1 in 2012 which gives a reason to assume that aging is not an important determinant in the health deterioration. Still, the diseases most likely to be correlated with aging (both kinds of arthritis, fibromyalgia, debility, urinary incontinence, thyroid disease, high blood pressure and eye disease) have lower frequencies in Sample 2. Interestingly, higher frequency of diseases in Sample 2 is evident in all of the mental illness variables.

It is important to note that our study employs selfreported measures of the diseases and conditions of interest, which, although widely used, might pose problems to the reliability of the measurements. Differences in health assessment might e.g. be affected by differences in people's health awareness and evaluation, particularly since many of the health variables in question are conditions, rather than diseases. Moreover, one could even speculate whether such differences might be related to socio-economic status, which would further bias our measurements. Some conditions that have been of 
interest in previous research on business cycles and health are unfortunately omitted in this research, for example suicides, traffic accidents and infant mortality. How business cycles affect the distribution of those conditions across socioeconomic groups would however be of interest and we encourage future research on those topics.

The aging of the sample over the 5 year period can also be mentioned as a potential drawback to our study as the increase in the income-related inequality in health may partly be driven by the aging. One obvious reason for this is that as people grow older they are more likely to have worse health, and when they retire they tend to drop in their income ranking, which affects the incomerelated health inequality [65]. However, aging has also been found to increase the inequality before retirement. Deaton and Paxson [66] studied approximately 50.000 adults between the ages of twenty and seventy over the period of 1983 to 1994 . They used self-reported health status as the health measurement and found that a correlation between health and income increases with age, particularly from the age of twenty up until retirement age. They provide several possible explanations for this; they mention how earnings are adversely affected by negative health shocks and hence progressively correlated with age. As people's health after retirement does not affect income, they suggest that the correlation may weaken in very old age. They also evaluate possible causalities running from income to health such as how poorer people become more exposed to various risk factors with age and have more limited access to health care than their richer counterparts. As Sample 2 constitutes a group of participants in the same age range as that of Sample 1 in 2007, the presentation of this newest sample can be seen as our way to partly address this problem. Although not evident for females on average, Sample 2 has a slightly lower WCIs than Sample 1 does in 2012, which might give a reason to conjecture that the aging of the sample increases the income-related health inequality.

Our results suggest that the increase driven by the aging of the sample is more likely to be found in physical illness than mental illness, and especially evident in both kinds of arthritis, fibromyalgia and physical pain. Our standardized WCIs support these findings as they show that the contribution of age is stronger for men than women and much larger in the latter period than the first. Especially, the contribution of age increases the WCIs of Sample 1 in 2012. Thus, the increase in men's income-related health inequality over the latter period is exaggerated by the aging of the sample. Consequently, as the overall increase in the income-related health inequality between 2009 and 2012 is driven by the biased increase in men's inequality, it also needs to be discounted.

\section{Conclusions}

By analyzing the period between 2007 and 2012 in Iceland, we show that the economic collapse increased female income-related health inequality but decreased that of men. These changes, which are largely driven by the trends in mental health inequality, reversed during the economic recovery period. Overall, we find a considerable incomerelated health inequality which increased steadily over the whole study period. Our results conform and contribute to a range of other studies on income-related inequality in health; they provide evidence of the effects of an economic collapse and a recovery on the distribution of thirty different diseases along the income spectrum. As many of the impacts and trends in the WCIs are still unexplained, a decomposition of all the WCIs would be a logical next step in order to provide a clearer picture of the main determinants of the income-related health inequality. Given the range of diseases and conditions examined within this study, such an analysis is beyond the scope of this paper, but encouraged.

\section{Acknowledgements}

We thank the Directorate of Health in Iceland for providing the data.

\section{Funding}

We are grateful for having received funding from The Icelandic Student Innovation Fund (application number 1536030091) and from The Icelandic Research Fund - Icelandic Center for Research (IRF grant number 130611-052) to support assistantship by Hildur Margrét Jóhannsdóttir.

\section{Authors' contributions}

The authors both collectively collaborated on all sections of the paper. Large portions of the work were executed by HMJ while supervised by TLA. Both authors read and approved the final manuscript.

\section{Competing interests}

The authors declare that they have no competing interests.

Received: 22 December 2016 Accepted: 27 February 2017 Published online: 09 March 2017

\section{References}

1. Ruhm CJ. Healthy living in hard times. J Health Econ. 2005;24(2):341-63. doi:10.1016/j.jhealeco.2004.09.007.

2. Wilkinson RG. Unfair shares: the effects of widening income differences on the welfare of the young. J Soc Policy. 1994;24(4):577-8. doi:10.1017/ S0047279400025472

3. Wilkinson RG, Pickett KE. Income inequality and population health: a review and explanation of the evidence. Soc Sci Med. 2006;62(7):1768-84. doi:10.1016/j.socscimed.2005.08.036

4. Wilkinson RG, Pickett KE. Income inequality and health: A causal review. Soc Sci Med. 2015;128:316-26. doi:10.1016/j.socscimed.2014.12.031.

5. Berkman ND, Sheridan SL, Donahue KE, Halpern DJ, Crotty K. Low health literacy and health outcomes: an updated systematic review. Ann Intern Med. 2011;155(2):97-107. doi:10.7326/0003-4819-155-2-201107190-00005.

6. Kawachi I, Adler NE, Dow WH. Money, schooling, and health: Mechanisms and causal evidence. Ann N Y Acad Sci. 2010;1186:56-68. doi:10.1111/j.17496632.2009.05340.x

7. Marmot MG, Rose G, Shipley M, Hamilton PJS. Employment Grade and Coronary Heart Disease in British Civil Servants. J Epidemiol Commun H. 1978;32(4):244-9.

8. Marmot MG, Smith GD, Stansfeld S, Patel C, North F, Head J, White I, Brunner E, Feeney A. Health Inequalities among British Civil Servants: The Whitehall II Study. Lancet. 1991;337(8754):1387-93.

9. Ruhm CJ, Cawley J. The economics of risky health behavior. Handb Health Econ. 2011;2:95-199. doi:10.3386/w17081. 
10. Wagstaff A, van Doorslaer E. Income inequality and health: what does the literature tell us? Annu Rev Publ Health. 2000;21:543-67. doi:10.1146/ annurev.publhealth.21.1.543.

11. Babones SJ. Income inequality and population health: correlation and causality. Soc Sci Med. 2008;66(7):1614-26. doi:10.1016/j.socscimed.2007.12.012.

12. Van Doorslaer E, Wagstaff A, Bleichrodt H, Calonge S, Gerdtham UG, Gerfin M, Geurts J, Gross L, Häkkinen U, Leu RE, O'Donnell O, Propper C, Puffer F, Rodriguez M, Sundberg G, Winkelhake O. Income-related inequalities in health: Some international comparisons. J Health Econ. 1997;16(1):93-112. doi:10.1016/S0167-6296(96)00532-2.

13. Asgeirsdóttir TL, Ragnarsdóttir DÓ. Determinants of relative and absolute concentration indices: evidence from 26 European countries. Int J Equity Health. 2013;12:53. doi:10.1186/1475-9276-12-53.

14. Bambra C, Eikemo TA. Welfare state regimes, unemployment and health: a comparative study of the relationship between unemployment and selfreported health in 23 European countries. J Epidemiol Commun H. 2009;63: 92-8. doi:10.1136/jech.2008.077354.

15. Eikemo TA, Bambra C, Huisman M, Kunst AE. Health inequalities according to educational level in different welfare regimes: a comparison of 23 European countries. Sociol Health III. 2008;30(4):565-82. doi:10.1111/j.1467-9566.2007.01073.x.

16. Eikemo TA, Bambra C, Joyce K, Dahl E. Welfare state regimes and income-related health inequalities: a comparison of 23 European countries. Eur J Public Health. 2008;18:593-9. doi:10.1093/eurpub/ckn092.

17. Mackenbach JP, Stirbu I, Roskam AJR, Schaap MM, Menvielle G, Leinsalu M, Kunst AE. Socioeconomic inequalities in health in 22 European countries. New Engl J Med. 2008;358:2468-81. doi:10.1056/NEJMsa0707519.

18. Van Doorslaer $\mathrm{E}$, Koolman X. Explaining the differences in income-related health inequalities across European countries. Health Econ. 2004;13(7):609-28. doi:10.1002/hec.918.

19. Ariizumi H, Schirle T. Are recessions really good for your health? Evidence from Canada. Soc Sci Med. 2012;74(8):1224-31. doi:10.1016/j.socscimed.2011.12.038.

20. Granados JAT. Death Rates and Business Cycle Fluctuations in Spain at the End of the 20th Century: Further Empirical Evidence of the Mortality Increase During Economic Expansions. New York City: Mimeo, New School University; 2002.

21. Granados JAT. Increasing mortality during the expansions of the US economy, 1900-1996. Int J Epidemiol. 2005;34(6):1194-202. doi:10.1093/ije/dyi141.

22. Granados JAT. Recessions and mortality in Spain, 1980-1997. Eur J of Popul. 2005;21:393-422. doi:10.1007/s10680-005-4767-9.

23. Granados JAT. Macroeconomic fluctuations and mortality in postwar Japan. Demography. 2008;45(2):323-43. doi:10.1353/dem.0.0008.

24. Neumayer E. Recessions lower (some) mortality rates: evidence from Germany. Soc Sci Med. 2004;58:1037-47. doi:10.1016/S0277-9536(03)00276-4.

25. Ruhm CJ. Economic Conditions and Alcohol Problems. J Health Econ. 1995; 14(5):583-603. doi:10.3386/w4914.

26. Ruhm CJ. Are recessions good for your health? Q J Econ. 2000;115(2):617-50. doi:10.1162/003355300554872.

27. Ruhm CJ, Gerdtham UG. Deaths rise in good economic times: evidence from the OECD. Econ Hum Biol. 2006:4(3):298-316. doi:10.3386/w9357.

28. Gruber J, Frakes M. Does Falling Smoking Lead to Rising Obesity? J Health Econ. 2006;25(2):183-97. doi:10.3386/w11483.

29. Xu X, Kaestner R. The Business Cycle and Health Behaviors. No. 15737, NBER Working Papers. National Bureau of Economic Research. 2010. http://www. nber.org/papers/w15737. Accessed 12 Apr 2016

30. Courtemanche C. Longer Hours and Larger Waistlines? The Relationship Between Work Hours and Obesity. Forum Health Econ Pol. 2009;12(2):2-2. doi:10.2139/ssrn.975099.

31. Edwards R. Who is hurt by procyclical mortality? Soc Sci Med. 2008;67:2051-8. doi:10.1016/j.socscimed.2008.09.032.

32. Edwards R. American Time Use Over the Business Cycle. New York City: Mimeo, Queens College, CUNY; 2011.

33. Baker DB. The Study of Stress at Work. Ann Rev Publ Health. 1985;6:367-81. doi:10.1146/annurev.pu.06.050185.002055.

34. Karasek RA, Theorell T. Healthy Work: Stress, Productivity, and the Reconstruction of Working Life. New York: Basic Books; 1990.

35. Sokejima S, Kagamimori S. Working Hours as a Risk Factor for Acute Myocardial Infarction in Japan: A Case-control Study. British Med J. 1998;317(7161):775780 http://www.jstor.org/stable/25180423 Accessed 1 Mar 2016

36. Ruhm CJ. Recessions, healthy no more? J Health Econ. 2015;42:17-28. doi:10.1016/j.jhealeco.2015.03.004

37. Stevens AH, Douglas LM, Page M, Filipski M. The best of times, the worst of times: understanding pro-cyclical mortality. Am Econ J. 2011;7(4):279-311. doi:10.3386/w17657.
38. Economou A, Nikolaou A, Theodossiou I. Are recessions harmful to health after all?: Evidence from the European Union. J Econ Stud. 2008;35(4):368-84. doi:10.1108/01443580810903536.

39. Mclnerney M, Mellor JM. Recessions and seniors' health, health behaviors, and healthcare use: analysis of the medicare beneficiary survey. J Health Econ. 2012;31(5):744-51. doi:10.1016/j.jhealeco.2012.06.002.

40. Ásgeirsdóttir TL, Ragnarsdóttir DÓ. Health-income inequality: the effects of the Icelandic economic collapse. Int J Equity Health. 2014;13:1-23. doi:10.1007/s11150-013-9225-6.

41. Asgeirsdóttir TL, Eiríksdóttir VH, Bjarnadóttir RI, Kaestner R, Cnattingius S, Valdimarsdóttir UA. Low Birth Weight, Small for Gestational Age and Preterm Births Before and After the Economic Collapse in Iceland: A Population Based Cohort Study. PLoS ONE. 2013:8:12. doi:10.1371/journal.pone.0080499.

42. Asgeirsdóttir TL, Eiríksdóttir VH, Valdimarsdóttir UA, Hauksdóttir A, Lund SH, Bjarnadóttir Rl, Cnattingius S, Zoega H. Pregnancy-Induced Hypertensive Disorders before and after a National Economic Collapse: A Population Based Cohort Study. PLoS ONE. 2015;10:9. doi:10.1371/journal.pone.0138534.

43. Ásgeirsdóttir TL, Jónsdóttir S. The Effect of Job Loss on Body Weight During an Economic Collapse. Eur J Health Econ. 2014;15(6):567-76. doi:10.1007/ s10198-013-0494-z.

44. Ásgeirsdóttir TL, Ólafsdóttir P, Ragnarsdóttir DÓ. Business Cycles, Hypertension and Cardiovascular Disease: Evidence from the Icelandic Economic Collapse. Blood Press. 2014;23(4):213-21. doi:10.3109/08037051. 2013.862913.

45. Ásgeirsdóttir TL, Berndsen HH, Guðmundsdóttir BP, Gunnarsdóttir BA, Halldórsdóttir HJ. The effect of obesity, alcohol misuse and smoking on employment and hours worked: evidence from the Icelandic economic collapse. Rev Econ Household. 2016;14(2):313-35. doi:10.1007/s11150-013-9225-6.

46. Ásgeirsdóttir TL, Corman H, Noonan K, Reichman N. Lifecycle Effects of a Recession on Health Behaviors: Boom, Bust, and Recovery in Iceland. Econ Hum Biol. 2016;20:90-107. doi:10.3386/w20950.

47. Ásgeirsdóttir TL, Corman H, Noonan K, Ólafsdóttir P, Reichman N. Was the Economic Crisis of 2008 Good for Icelanders? Impact on Health Behaviors. Econ Hum Biol. 2014;13:1-19. doi:10.1016/j.ehb.2013.03.005.

48. Ásgeirsdóttir TL, Ólafsdóttir P. Gender differences in drinking behavior during an economic collapse: evidence from Iceland. Rev Econ Household. 2015;13(4):975-1001. doi:10.1007/s11150-015-9283-z.

49. Ásgeirsdóttir TL, Ólafsdóttir P, Hrafnkelsson B. The Icelandic Economic Collapse, Smoking and the Role of Labor-Market Changes. Eur J Health Econ. 2014;16(4):391-405. doi:10.1007/s10198-014-0580-x.

50. Ásgeirsdóttir TL, Tryggvason Á. Hagsveiflur og vinnuslys á Íslandi 1986-2011. Stjórnmál og stjórnsýsla. 2014;10(2):399-426.

51. The World Bank. World development indicators: Google public data explorer. 2014. http://www.google.com/publicdata/explore?ds= d5bncppjof8f9_\&met_y=ny_gdp_mktp_kd_zg\& idim = country:USA:IND: GBR\&hl = en\&dI = en\#!ctype = $\mid \&$ strail $=$ false\&bcs $=$ d\&nselm $=$ h\&met_y = ny_g dp_mktp_kd_zg\&scale_y $=$ lin\&ind_y $=$ false\&rdim $=$ region\&idim = country:USA:IND:GBR:ISL:ESP:IRL \&ifdim = region\&hl = en_US\&dl = en\&ind = false. Accessed 2 Feb 2016

52. Statistics Iceland: Changes in CPI. Reykjavik: Statistics Iceland. 2016. http://px hagstofa.is/pxis/pxweb/is/Efnahagur/Efnahagur_visitolur____ visitalaneysluverds_1_neysluverd/VIS01000.px/Accessed 11 Apr 2016

53. Guðmundsson M. Iceland's crisis and recovery and current challenges. 2013. [Speech at a Conference organized by the French-Icelandic Chamber of Commerce; Islande, La Renaissance, Paris, 28 February 2013] http://www.bis. org/review/r130312d.pdf. Accessed 11 Mar 2016

54. Ólafsdóttir K. From recession to growth: Recovery in the labor market. [Guest lecture at Universita di Perugia, Perugia, 15 April 2013]. 2013. http:// www.ec.unipg.it/DEFS/uploads/katrin-2-from_recession_to_growth-2.pdf. Accessed 6 Mar 2017.

55. OECD: Framework for Statistics on the Distribution of Household Income, Consumption and Wealth. Paris: OECD Publishing; 2013. doi: 10.1787/ 9789264194830-en

56. Kakwani NC. Measurement of Tax Progressivity: An International Comparison. Econ J. 1977;87(345):71-80. doi:10.2307/2231833.

57. Kakwani NC, van Doorslaer E, Wagstaff A. Socioeconomic Inequalities in Health: Measurement, Computation and Statistical Inference. J Econometrics. 1997;77(1):87-104. doi:10.1016/S0304-4076(96)01807-6.

58. O'Donnell O, Van Doorslaer E, Wagstaff A, Lindelow M. Analyzing Health Equity Using Household Survey Data. Washington: The International Bank for Reconstruction and Development/The World Bank; 2008. p. 95-114. 
59. Wagstaff A, Paci P, van Doorslaer E. On the Measurement of Inequalities in Health. Soc Sci Med. 1991;33(5):545-57. doi:10.1016/0277-9536(91)90212-U.

60. Wagstaff A. The bounds of the concentration index when the variable of interest is binary, with an application to immunization inequality. Health Econ. 2005;14(4):429-32. doi:10.1002/hec.953.

61. StataCorp. Stata Statistical Software: Release 13. StataCorp, LP. Texas: 20 College Station; 2013.

62. Kentikelenis A, Karanikolos M, Papanicolas I, Basu S, McKee M, Stuckler D. Health effects of financial crisis: omens of a Greek tragedy. Lancet. 2011; 378(9801):1457-8. doi:10.1016/S0140-6736(11)61556-0.

63. Gili M, Roca M, Basu S, McKee M, Stuckler D. The mental health risks of economic crisis in Spain: evidence from primary care centres, 2006 and 2010. Eur J Public Health. 2013;23:103-8. doi:10.1093/eurpub/cks035.

64. Karanikolos M, Mladovsky P, Cylus J, Thomson S, Basu S, Stuckler D, Mackenbach JP, McKee M. Financial crisis, austerity, and health in Europe. Lancet. 2013;381 (9874):1323-31. doi:10.1016/50140-6736(13)60102-6.

65. Islam MK, Gerdtham U, Clarke P, Burström K. Does income-related health inequality change as the population ages? Evidence from Swedish pane data. Health Econ. 2010;19:334-49. doi:10.1002/hec.1479.

66. Deaton AS, Paxson CH. Aging and Inequality in Income and Health. Am Econ Rev, Papers and Proceedings. 1998;88(2):248-253. https:/www.princeton.edu/ deaton/ downloads/Aging_and_Inequality_in_Income_and_Health.pdf Accessed 13 Mar 2016

\section{Submit your manuscript to a SpringerOpen ${ }^{\circ}$ journal and benefit from:}

- Convenient online submission

- Rigorous peer review

- Immediate publication on acceptance

- Open access: articles freely available online

- High visibility within the field

- Retaining the copyright to your article

Submit your next manuscript at $\boldsymbol{s p r i n g e r o p e n . c o m ~}$ 